THÉMATA. Revista de Filosofía

No49, Enero-junio (2014) pp.: 271-291

ISSN: 0212-8365 e-ISSN: 2253-900X

doi: 10.12795/themata.2014.i49.15

\title{
REALISMO CONTRA IDEALISMO EN LAS NEUROCIENCIAS DE LA VISIÓN
}

\author{
REALISM AGAINST IDEALISM IN NEUROSCIENCE OF VISION
}

\author{
Desiderio Parrilla Martínez ${ }^{1}$ \\ Universidad Católica san Antonio de Murcia (España)
}

Recibido: 24-05-2013

Aceptado: 25-07-2013

Resumen: Las neurociencias actuales están favoreciendo una recuperación del realismo gnoseológico. El artículo muestra cómo el idealismo filosófico ha dominado tradicionalmente el estudio del cerebro, así como el proceso que está permitiendo este cambio de paradigma.

Palabras-clave: Realismo, idealismo, visión, neurociencia, cerebro.

\begin{abstract}
The current neurosciences are favoring a recovery of epistemological realism. This article shows how the study of the brain was traditionally dominated by philosophical idealism, and the process that is enabling this shift of paradigm.
\end{abstract}

Key-words: Realism, idealism, vision, neuroscience, brain.

El filósofo Roberto Saumells, al impugnar el paradigma computacional sobre la percepción visual en neurociencia, hace suya la opinión que Wittgenstein adoptaba respecto al mismo tema: "con respecto al concepto de "ver", el len-

[1] (dparrilla@ucam.edu) Desiderio Parrilla Martínez (Madrid, 1975), es doctor en Filosofía por la Universidad Complutense de Madrid con la tesis: "La paradoja del deseo en René Girard". Ha sido profesor del Instituto de Humanidades Ángel Ayala de la Universidad San Pablo-CEU (2003-2004). Ejerció como profesor en la Universidad Francisco de Vitoria de Madrid (20072010). Desde el curso 2010, trabaja como profesor adjunto del departamento de humanidades en la Universidad Católica de Murcia (UCAM). Vicepresidente de la asociación de estudios girardianos Xiphias Gladius (http://www.xiphiasgladius.es/inicio.html), asociada al grupo internacional de investigación Imitatio (http://www.imitatio.org/). Orienta su labor investigadora hacia la escolástica y la filosofía en español. 
guaje ingenuo, es decir, nuestra forma ingenua, normal, de expresarnos no contiene una teoría del ver. Muestra, no una teoría, sino sólo un concepto del ver»².

Para Saumells, las teorías neurocientíficas actuales, influidas por el mecanicismo o el modelo idealista del "procesamiento de información", resultan respecto al fenómeno psicobiológico de la visión tan ingenuas como las explicaciones del hombre más profano. El eminente neurobiólogo de la visión, Semir Zeki suscribe esta opinión cuando reflexiona sobre «la pobreza de nuestro lenguaje neural» ${ }^{3}$, por lo demás, uno de los tópicos de la divulgación neurocientífica más reputada ${ }^{4}$.

La teoría del "New look", o realismo inmediato, es en su base un intento de superar dichas ingenuidades y, en su cumbre, un primer movimiento hacia una teoría del sujeto psicobiológico a través de una formulación cabal del acto de ver.

Para cumplir con este objetivo, el hiperrealismo neurocientífico manifiesta la ingenuidad de las tesis representacionistas, así como el idealismo gnoseológico implícito en las teorías del "procesamiento de información”, tal como fue acuñada por David Marr en su libro Vision, la biblia del paradigma computacional en neurociencia de la visión ${ }^{6}$.

La teoría alternativa que el hiperrealismo propone es heredera de una notable tradición neurocientífica7. Entronca directamente con el "funcionalismo probabilista" de Egon Brunswik y sus intentos por superar el conductismo, a través de teorías como la "co-presencia a distancia" ("relaciones a distancia"), los "objetos apotéticos" y el "funcionalismo ambiental".

El hiperrealismo asimila la aportación de este "transaccionismo" para evitar tanto el dualismo en la relación mente-cerebro como el monismo fisicalista en cualquiera de sus modalidades (epifenomenismo, monismo eliminatorio, emergentismo, paralelismo psico-físico, etc. $)^{9}$. Su obra está influida tam-

[2] Wittgenstein, L.: Observaciones sobre filosofía de la psicología. Méjico: UNAM, 1997, v. I, § 1101.

[3] Zeki, S.: Una visión del cerebro. Barcelona, Ariel, 1995, pp. 17-24. Ibídem: «La imagen visual en la mente y en el cerebro", en Investigación y ciencia, No 194, 1992, pp. 26-35.

[4] Cfr. Hubel, D. H.: Ojo, cerebro y visión. Barcelona: Ed. Investigación y ciencia, p. 221. Frisby, J. P.: Del ojo a la visión. Madrid: Alianza, 1987, pp. 207-212.

[5] Cfr. Hochberg J. E.: La percepción, México: Ed. UTEHA, 1968. Bruce Goldstein, E.: Sensación y percepción. Méjico: International Thomson Editores, 2006, pp. 301-324.

[6] Marr, D.: Visión: una investigación basada en el cálculo acerca de la representación y el procesamiento humano de la información visual. Madrid: Alianza, 1985. Cfr. Brady, M.: «Computational vision», en: Broadbent, D. (ed.): The simulation of human intelligence. Oxford: Blackwell, 1993.

[7] Luna, D. y Tudela, P.: Percepción visual. Madrid: Trotta, 1995. Bruce, V. y Green, P. R.: Percepción visual: Manual de fisiología, psicología y ecología de la visión. Barcelona: Paidós, 1994.

[8] Brunswik, E.: "distal focuding of perception: size-constancy in a representative sample of situations”, Psychol. Monog., 56, n² 254, p. 49. Fuentes Ortega, J. B.: “¿Funciona de hecho la psicología empírica como una fenomenología del comportamiento?», en: Brunswik, E., El marco conceptual de la psicología. Madrid: Debate, 1989, pp. 7-78.

[9] Cfr. González Quirós, J. L.: Mente y cerebro. Madrid: Iberediciones, 1994.

THÉMATA. Revista de Filosofía, Nº49 enero-junio (2014) pp.: 271-291

doi: 10.12795/themata.2014.i49.15 
bién por los herederos de Brunswik (Jerome James Gibson, Roger G. Barker o Herbert F. Wright) que formularon la teoría de la "percepción directa"10.

El hiperrealismo concibe la actividad cerebral como el puente tendido entre el acto inmediato de ver y la conducta operatoria del organismo. La actividad cerebral se limita a vincular dos dimensiones autónomas tales como son: 1) el acto psicobiológico de ver y 2) las operaciones corpóreas que el organismo animal emprende en su medio entorno (Umwelt).

Desde esta perspectiva, niega la tesis idealista de que la mente sea un producto cerebral. El cerebro, por tanto, no produce la visión. La experiencia visual es un dato inmediato de conciencia que no se realiza "en" el cerebro. La actividad cerebral no es un "procesamiento de información" a través de circuitos neuronales que analizan y reconstruyen computacionalmente imágenes subjetivas a partir de datos obtenidos de la realidad exterior y que se proyectarían -no se sabe bien cómo- de nuevo hacia el exterior en perspectiva caballera.

En esta catena aurea que recupera el realismo para las neurociencias habría que incluir, por supuesto, a Henri Bergson, quien hace una contribución filosófica decisiva para esta tradición, equiparable a cualquier otra aportación precedente o posterior, incluyendo la propia "lógica ecológica", o "semántica de situaciones", de Jon Barwise y John Perry ${ }^{11}$, que a principios de los años 1980 probó a axiomatizar la teoría ecológica de la visión directa de J. J. Gibson. En este afán por superar el mecanicismo anti-mentalista, el hiperrealismo entronca, como veremos, con algunos de los neurocientíficos más destacados en la investigación relativa a la percepción visual (Hubel y Wiesel, Sperry, Semir Zeki, y otros).

\section{Realismo e idealismo en neurociencia}

En su polémica con Michael Dummett sobre el realismo científico, Hilary Putnam ${ }^{12}$ mantenía un realismo de alcance ontológico como el que se está abriendo paso en las neurociencias actuales. Los enunciados de la ciencia -afirmaba Putnam- son verdaderos o falsos; y su verdad o falsedad no consiste en que describan regularidades de la experiencia humana. Porque la realidad no es una parte de la mente humana sino que la mente humana es una parte de la realidad. John D. Barrow resumió esta postura realista de un modo icástico: "no preguntes qué hay dentro de la cabeza sino dentro de qué está la cabeza» ${ }^{13}$.

[10] Gibson, J. J.: La percepción del mundo visual. Ed. Infinito: Buenos aires, 1974.

[11] Barwise, J. y Perry, J.: Situaciones y actitudes. Madrid: Ed. Visor, 1992, pp. 9-10. Ibídem: "Situations and attitudes", en Journal of philosophy, 78, n 11, 1981, pp. 668-691.

[12] Putnam, H.: Mind, language and reality, Philosophical papers I. Cambridge: University Press, 1979, VII, pp. 97-199.

[13] Barrow, J. D.: La Trama Oculta Del Universo. Barcelona, Ed. Critica, 2001, p. 280.

THÉMATA. Revista de Filosofía, Nº49 enero-junio (2014) pp.: 271-291

doi: 10.12795/themata.2014.i49.15 
El principio de inmanencia constitutivo de la edad moderna postula que la realidad es un producto mental; apela a un principio cognoscitivo que es fuente del orden inmanente de las apariencias. El representacionismo moderno concibe el cerebro como la sede o el ámbito de un mundo subjetivo o privado cuyos "contenidos psíquicos" resultan accesibles sólo a la introspección. De esta manera, algo es un objeto en cuanto está puesto ante sí por un sujeto cognoscente, bien mediante una instancia mental o espiritual (Descartes, Kant, Eccles), bien naturalista como el cerebro (Hume, Feuerbach, Vogt, Dretske), bien mediante el trabajo y las condiciones sociales de producción ("retina social" de D. Lowe), etc.

La reducción de las apariencias a sus respectivos correlatos cerebrales comenzó a llevarse a cabo de modo grosero y pre-científico por la frenología de Gall o de Spurtzheim, y llegó hasta el nivel del idealismo absoluto y el solipsismo con la inmanencia de las imágenes intracraneanas, en torno a las cuales giró la argumentación de Schubert-Soldern o Wilhelm Schuppe. A continuación mostraremos el proceso histórico mediante el cual se introdujo en psicobiología de la visión este modelo idealista, y cómo se ha perpetrado, por contra, el regreso hacia el realismo óptico.

La oftalmología, junto a la óptica geométrica, se cerró como tal ciencia positiva a través de una metáfora fundacional: la consideración del ojo como una cámara oscura ${ }^{14}$. La inspiración inicial surgió de G. B. Porta (1536-1615), quien en su "magia naturalis" exponía exhaustivamente las propiedades de esta "caja estenopeica". Con antecedentes ilustres como Kirscher, Scheiner o Kepler, fue sin embargo Descartes quien extrajo su mayor rendimiento como analogía óptica y estableció el modelo de la "cámara oscura" para elaborar su Dióptrica ${ }^{15}$.

Según Anthony Kenny ${ }^{16}$, los errores de Descartes acerca de la representación -y en especial de la naturaleza de la representación sensible- tuvieron mucha influencia, en parte, porque en su trabajo experimental realizó esta significativa contribución a la ciencia. Efectivamente, fue el primero que estableció algorítmicamente la naturaleza de las imágenes en la retina, aplicando la geometría analítica al ojo anatómicamente manipulado. Extirpó el fondo retiniano de un ojo de buey y lo reemplazó por un papel traslúcido. Manteniendo el ojo en un cuarto a oscuras frente a la luz exterior que penetraba por un orificio de la pared, pudo ver una imagen invertida de la habitación contigua proyectada sobre el papel. Con la institución del horóptero, Descartes tuvo el mérito de trasladar al plano geométrico los teoremas, proposiciones, escolios y

[14] Cfr. Polyak, S.: The vertebrate visual system, Chicago, University of Chicago Press, 1957.

[15] Descartes, R.: Dióptrica. Alfaguara: Madrid, 1991, V, VI. Cfr. Newton, I.: Óptica. Madrid: Alfaguara, 1977, libro I, parte I, axioma VII.

[16] Kenny, A.: The Metaphysics of Mind. Oxford: Oxford University Press, 1992, p. 34.

THÉMATA. Revista de Filosofía, Nº49 enero-junio (2014) pp.: 271-291

doi: 10.12795/themata.2014.i49.15 
corolarios de este modelo inicial, donde el axioma central era la consideración del ojo como una "cámara oscura"17. Este descubrimiento -como indica Kennyconstituyó al mismo tiempo una importante contribución a la óptica geométrica y la fuente incidental de una serie subsecuente de errores filosóficos ${ }^{18}$.

El error más decisivo fue la introducción del idealismo mediatista en la psicología experimental ${ }^{19}$. Este modelo de la cámara oscura junto al idealismo filosófico fue asimilado por los primeros psicólogos experimentales a través del magisterio kantiano, que pasó desde Herbart hasta Wundt, pasando por Lotze o Johannes Müller ${ }^{20}$. La psicología positiva, lastrada por este representacionismo, sostendrá que las percepciones son unos estados mentales que las cosas producen en nosotros, las cuales quedan por tanto allende la percepción misma. La percepción y la sensación serían la manera representativa como las cosas están en nosotros como contenidos de nuestra mente. El equívoco inicial no hizo sino agravarse cuando se instituyó la especialidad académica de la "psicofísica" con Weber, Fechner o Volkmann, pues sus fundadores adoptaron el modelo idealista como un dogma incontestable para la "óptica psicofísica" ${ }^{21}$. Así Mach, como iniciador de esta disciplina aplicada a la visión, sitúa el modelo cartesiano en su centro: «El experimento de la cámara oscura es también importante desde el punto de vista teórico: muestra por primera vez de una manera indudable, que la luz procede en forma de rayos rectilíneos incluso en el caso de objetos iluminados» ${ }^{22}$.

Coincidiendo con el desarrollo de la teoría electromagnética y las ecuaciones de Maxwell-Hertz, surge la óptica neurológica, u óptica fisiológica ${ }^{23}$, de manos de Hermann von Helmholtz, Ewald Hering, Louis Verrey, Salomon E. Henschen, Constantine von Monakov, etc. El modelo idealista no pierde su vigencia, antes bien se incrementa. El modelo origina teorías tales como la

[17] Graham, Ch.: Vision and visual perception. NY: John Wiley and Sons, 1965.

[18] Berkeley, G.: Ensayo de una nueva teoría de la visión. Madrid: Aguilar, 1973, LXXXVIII-CLX.

[19] Merleau-Ponty, M.: El ojo y el espíritu. Barcelona: Paidós, 1986. Magnard, P.: «L’instuitus mentis et la visión aveugle», en: La passion de la raison. París: PUF, 1983, pp. 79-95. Marion, J. L.: Sur la theologie blanche de Descartes. París: PUF, 1981, p. 242.

[20] Benton, A.: History of Neuropsychology: Selected Papers. NY: Oxford, 2000, pp. 104-144. Cfr. Finger, S.: Minds Behind the Brain: A History of the Pioneers and their discoveries. NY: Oxford, 2000. Ibídem: Origins of neuroscience : a history of explorations into brain function. NY: Oxford, 1994.

[21] Jung, R.: «Sensory research in historical perspective: some philosophical foundations of perception", en: Darian-Smith, I (ed.): Handbook of Physiology, American Physiological Society. Maryland: Bethesda, 1984, pp. 1-74. Geischeider, G. A.: Psychophysics: The Fundamentals. New Jersey: Erlbaum, 1997. Schwartz, S. H.: Visual Perception: a clinical orientation. Connecticut: Appleton and Lange, 1999.

[22] Mach, E.: The principles of phisical optics. Londres: Dover publications, 2003, pp. 12ss.

[23] Jeannerod, M.: De la physiologie mentale. Historie des relations entre la phychologie et la biologie. París: Odile Jacob, 1996.

THÉMATA. Revista de Filosofía, Nº49 enero-junio (2014) pp.: 271-291

doi: 10.12795/themata.2014.i49.15 
teoría retinex, la actividad cerebral paralela, el funcionamiento multifásico integrado, etc ${ }^{24}$. Determina conceptos de gran sabor idealista como: "impresión visual en la retina", "imagen, o afección, retiniana", "signo local", "meta-retina puramente psicológica", "retina cortical en relación isomorfa con la retina ocular", "repleción del punto ciego", "reproducción isológica del objeto externo en el cerebro", "copia cortical del objeto real", "proyección del objeto en la zona occipital o segunda retina", etc. Tales conceptos se organizan en diversos sistemas que tratan de conciliar el modelo nigrocameral con las aportaciones de la electrodinámica y la neurofisiología decimonónicas, aunque siempre presididos por el inveterado idealismo moderno. Se trataba, en suma, de conectar la imagen "percibida" en la retina con la actividad cerebral nerviosa en las áreas cerebrales especializadas en la visión.

La óptica neurofisiológica, tras la invención de la fotografía, cambia este modelo renacentista de la caja negra y explica la visión natural a partir del modelo de la cámara fotográfica. Se dirá que el ojo equivale a una cámara fotográfica, en cuanto tiene un sistema de cuatro lentes: 1) la interfase entre el aire y superficie anterior a la córnea; 2) la interfase entre la superfie posterior de la córnea y el humor acuoso; 3) la interfase entre el humor acuoso y la superficie anterior del cristalino; 4) la interfase entre la superficie posterior al cristalino y el humor vítreo. El ojo tiene también -se dirá- como la cámara fotográfica un sistema de abertura variable (iris/diafragma) y una retina, que correspondería a la placa fotográfica. Incluso a la primera capa pigmentada (melanina) de la retina se le asignará una función análoga a la que desempeña la pintura negra dentro del fuelle de una máquina fotográfica. Así como la lente de vidrio de la cámara fotográfica puede enfocar la imagen sobre un papel, el sistema de lentes del ojo puede enfocar una imagen sobre la retina, una imagen invertida respecto del objeto. La retina, como la placa fotosensible de la cámara fotográfica, se excita químicamente, generándose así un potencial en los bastones y conos (unos 125 millones en cada retina, más 5,5 millones de conos) que se transmite aplicativamente (aunque puede ser de varios a uno: de la retina sólo salen 900 mil fibras ópticas, lo que indica que unos 140 bastones y 6 conos convergen en cada fibra) a la corteza visual primaria V1 (la "retina cortical" de Henschen), situada en la fisura calcarina, que se localiza a cada lado de la superficie interna de cada corteza occipital. La "teoría retinex" llegó a forzar tanto la metáfora que consideraba la imagen de la corteza visual primaria equivalente a la placa revelada, puesto que el revelado analógico también necesitaba hacer intervenir a las áreas de asociación visual (V1 y V2 vinculada a colores y formas, lo mismo que V4 especializada en el cromatismo, V3 relacionada con las formas dinámicas y V5 encuadrada cómo área del movimiento). El idealismo se introducía en este modelo del "revelado fotográfico" de un modo ortodoxo: la imagen de la

[24] Zeki, S.: Una visión del cerebro. Barcelona: Ariel, 1995, pp. 25-297.

THÉMATA. Revista de Filosofía, Nº49 enero-junio (2014) pp.: 271-291

doi: 10.12795/themata.2014.i49.15 
retina ocular se identificaba con el carrete imprimado, o las placas sin revelar, y la actividad de la retina cortical se interpretaba como la máquina de revelado donde se obtendrían las imágenes visuales finalmente percibidas.

Podría decirse que cada nuevo instrumento óptico (cámara oscura, estereoscopio de Wheatstone, fantascopio de Robertson, fenaquistoscopio de Plateau, zootropo de Horner, iconoscopio de Zworykin, cámara fotográfica o cinematográfica, televisión, holograma...) han dado lugar a una teoría filosófica de la visión y, con ella, a nuevas determinaciones en neurociencia de las ideas de apariencia y verdad ${ }^{25}$. Así, el concepto de "área visual asociativa" de la corteza preestriada se establece por analogía con la caja de mezclas y la edición de montaje donde se construyen las imágenes del vídeo. La doctrina del procesamiento multifásico integrado de las regiones especializadas lleva implícito la circunstancia del paralelismo entre la complejidad del aparato de televisión que actúa detrás de la pantalla y la complejidad del cerebro que actúa "detrás de mis ojos". La dominancia binocular como causa de la visión tridimensional se establece por la homología entre el tubo de rayos catódicos y los dos nervios ópticos ${ }^{26}$. Los más de 100 millones de fotoreceptores de la retina del ojo son tematizados como un disco de Nipkov. Los movimientos oculares sacádicos se estudian como el movimiento de barrido del electrón sobre la pantalla para obtener el escaneado televisivo de las imágenes ${ }^{27}$. Las metáforas neotécnicas han sido, sin duda, contextos determinantes para la investigación neurológica.

Sin embargo, todas las analogías inherentes al modelo idealista dependen de una analogado principal, o prius, al que todas se subordinan: la consideración del ojo como una "cámara oscura", bajo una cláusula idealista: las apariencias serán entendidas como el reflejo inmediato de una realidad en nuestra retina ocular y posterior reproducción punto a punto de la imagen en la retina cortical. El reconocimiento del componente metafísico-idealista de las concepciones de Berkeley o Kant puede servirnos de canon para determinar hasta qué punto la psicobiología visual estuvo inspirada por el "idealismo de las apariencias". Un idealismo que se ha venido abajo por las realidades objetivas que las neurociencias desde mediados del siglo XX han subrayado en el proceso mismo de su constitución como disciplinas positivas.

Efectivamente, el paso desde la óptica psicofísica a la contemporánea disciplina de la neurología de la visión, u óptica fisiológica, hace entrar en crisis este modelo "cajanegrista" y su avatar fotográfico decimonónico, hasta perderse por completo en la segunda década de los años 1950, tras desechar también el mode-

[25] Bueno, G.: Televisión: apariencia y verdad. Barcelona: Gedisa, 2000, pp. 55-302.

[26] Martínez Verdú, F. M.: Fundamentos de visión binocular. Valencia: PUV, 2004, pp. 15-23.

[27] Pieratoni, R.: El ojo y la idea. Barcelona: Paidós, 1984, pp. 151ss.

THÉMATA. Revista de Filosofía, Nº49 enero-junio (2014) pp.: 271-291

doi: 10.12795/themata.2014.i49.15 
lo televisivo. El modelo que lo sustituyó entonces fue el de la cinematografía y, pasado el tiempo, el de la edición de vídeos y, más recientemente, el modelo computacional -según criterios clásicos ${ }^{28}$ o cuánticos ${ }^{29}-\mathrm{o}$, incluso, el holograma ${ }^{30}$.

El análisis de la visión desde la estructura de la televisión, el vídeo o el holograma, mantenían sin embargo el error cartesiano inicial. Todos estos modelos neotécnicos olvidan que la imagen invertida en el ojo de buey manipulado, o sobre la pantalla barrida por electrones, o como interfaz sobre el monitor de la computadora, o como escena en la placa holográfica, es una imagen $y a$ vista. De esta manera explican la visión por lo visto e incurren en un dialelo irresoluble.

Desde la década de 1970, el desarrollo de la nanobiología y las neurociencias cuánticas permite la acumulación de un acervo todavía más crítico contra estas posiciones idealistas adheridas a las investigaciones neurocientíficas. Para el hiperrealismo, estas aportaciones de la biología cuántica trituran definitivamente los últimos tópicos idealistas que parasitan estas disciplinas positivas. Los estudios de la óptica cuántica y la nanofisiología neural terminarían por liberar las actuales neurociencias del paradigma del ojo "como cámara" (oscura, fotográfica, de cine, vídeo, televisión...) y harían cada vez más evidente la pertinencia del "problema de Sherrington" establecido por Sir John Carew Eccles ${ }^{31}$.

Por simplificar al máximo la cuestión para las dimensiones de este artículo, expondremos tres de las consecuencias más drásticas contra el modelo idealista, que han sido esgrimidas por el hiperrealismo contemporáneo. Los argumentos pueden centrarse en la óptica y la neurofisiología, según su planteamiento disciplinar. Entre los argumentos ópticos, a su vez, pueden distinguirse los referidos a la óptica física y los propios de la óptica geométrica.

[28] George, F. H.: Cibernética y biología. Madrid: Alhambra, 1968, pp. 73-95.

[29] Deutsch, D.: "Quantum theory, the Church-Turing principle and the universal quantum computer", en Proceedings of the Royal Society of London, A400 (1818), July, 1985, pp. 97 117. Nielsen, M. y Chuang, I.: Quantum Computation and Quantum Information. Cambridge: Cambridge University Press, 2000. Rayo, A.: "Computación cuántica", Investigación y Ciencia, 405, junio 2010, pp. 92-93.

[30] Pribram, K. H.: Rethinking neural networks: quantum fields and biological data. Hillsdale: Erlbaum, 1993. Ibídem: Brain and perception: holonomy and structure in figural processing. Hillsdale: Erlbaum, 1991.

[31] Eccles, J. C.: Facing reality. Philosophical adventure by a brain scientist. NY: Springer, p. 170. Por "problema de Sherrington" se entiende la diferencia que separa las operaciones de la conciencia de la muy disímil realidad que constituyen los eventos de nuestro sistema nervioso central, especialmente en el cerebro. Era esta una cuestión donde el maestro de Eccles había insistido frecuentemente (Laslett, P. [ed.]: Las bases físicas de la mente. Buenos Aires: Nueva Visión, 1957, pp. 15-22), haciendo hincapié en el ámbito insular y aislable de la percepción visual (Hombres versus naturaleza. Barcelona: Tusquest, 1984, cap. 9-11). Ludwig von Bertalanffy se hace eco de este "salto insalvable entre el cerebro y la imagen directa" (Robots, hombres y mentes. Madrid: Guadarrama, 1971, p. 19).

THÉMATA. Revista de Filosofía, Nº49 enero-junio (2014) pp.: 271-291 doi: 10.12795/themata.2014.i49.15 


\section{Objeciones desde la óptica geométrica}

Comencemos por las objeciones referidas a la óptica geométrica que según el hiperrealismo disuelven los presupuestos gnoseológicos del idealismo óptico ${ }^{32}$.

En la geometría clásica, las operaciones de proyección y sección quedan ambas objetivadas como inmediatamente relacionadas en el seno de un espacio proyectivo previo. Así, por ejemplo, entre los postulados de la geometría sintética se establecerán por dualidad postulados como los siguientes: "tres puntos determinan un plano", o "tres planos determinan un punto", "una recta y un plano determinan un punto" y "una recta y un punto determinan un plano". Estos y otros enunciados definen, en conjunto, el espacio proyectivo.

La geometría descriptiva tiene por objeto proporcionar al técnico la manera de representar sobre un plano las diversas figuras del espacio a fin de poder resolver, utilizando solamente las construcciones de geometría plana, todos los problemas que puedan presentarse con los elementos del espacio. Los sistemas de proyección empleados en geometría descriptiva, son los siguientes: sistema diédrico, de doble proyección o de Monge; sistema acotado; sistema axonométrico; sistema cónico central.

En los tres primeros sistemas se utiliza la proyección ortogonal, mientras que en el cónico se emplea la proyección cónica o central, y es el empleado en el campo de la "óptica geométrica"

El teorema básico de la perspectiva o proyección central/cónica es el siguiente: "La proyección de un punto A del espacio sobre un plano de proyección $\alpha$, desde un punto fijo $\mathrm{O}$, exterior al plano de proyección, es la intersección $\mathrm{A} 1$ del rayo proyectante $\mathrm{OA}$ (determinado por $\mathrm{O}$ y el punto dado $\mathrm{A}$ ), con el plano a. El punto fijo $\mathrm{O}$ se llama centro de proyección, o nodo proyectante, y el plano a sobre el que se proyecta: «plano de proyección». El punto o’ definido por la intersección A1 sobre el «plano de proyección» a se denomina "sección proyectiva»".

Sin embargo, este teorema, válido en geometría, es ópticamente inaplicable. No hay sección óptica física a un haz de fotones, porque la luz, en la visión, no está en un espacio en cuyo seno tenga sentido la operación de una sección proyectiva ${ }^{33}$.

Dicho en concreto: el aparato fotográfico no hace la fotografía que creemos obtener de él; el aparato se limita a llevar a cabo una transferencia punto a punto desde los puntos de una superficie exterior a los puntos de una superficie del cliché fotosensible. Pero el plano de cliché ya no es una sección de la proyec-

[32] Saumells, R.: La intuición visual. Madrid: Parteluz, 1994, pp. 103-235. Ibídem: La ciencia y el ideal metódico. Madrid: Rialp, 1958, pp. 21ss. Cfr. Ibídem: Dialéctica del Espacio. Madrid: CSIC, 1953. [33]Jansson, G., Sture Bergström, S. y Epstein, W.: Perceiving: Events and Objects. Londres: Routledge, 1994, pp. 471-492.

THÉMATA. Revista de Filosofía, Nº49 enero-junio (2014) pp.: 271-291

doi: 10.12795/themata.2014.i49.15 
ción radial, sección que tenga sentido en un espacio proyectivo ulterior, pues este espacio, ópticamente, no existe. La imagen conjunta de la fotografía es únicamente la imagen de la operación visual que engloba, que integra a su modo esta dispersión físico-química de puntos proyectados desde el nitrato de plata hasta los puntos sensibles de la retina, los cuales, a su vez, constituyen otro nuevo centro de proyección y así hasta el infinito. La conciencia visual es el plano óptico que impide llevar hasta el infinito la sucesión de centros proyectivos, interrumpiendo las ondas que se propagan de manera isótropa, a través de la formación de la imagen, de modo análogo a como también englobará en un solo acto, en una imagen conjunta, los puntos temporalmente dispersos en la pantalla del televisor, en la pantalla del cine o las placas holográficas.

La categoría de "sección proyectiva" es una categoría válida dentro de la óptica geométrica. Pero esta categoría válida en la inmanencia de esta disciplina científica se hace inválida si tratamos de trasladarla como categoría propia de otras disciplinas científicas diferentes. Para el caso que nos ocupa, por ejemplo, esta categoría geométrica es inaplicable al electromagnetismo. En óptica electromagnética no hay sección geométrica de las ondas lumínicas. La onda electromagnética no tiene sección proyectiva, a diferencia del rayo proyectante en la óptica geométrica contra el plano clásico, o no-euclidiano.

Supone un error categorial hablar en óptica física de "cortadura de la continuidad sinocoidal de la onda electromagnética", porque la luz no tiene sección geométrica u óptica. Resulta un abuso afirmar que "los rayos de luz se cortan en la retina ocular" o que "las ondas electromagnéticas impresionan la retina" como si ésta fuera un plano geométrico y aquellas un rayo proyectante. La sección o cortadura geométrica A1 no es una categoría de la óptica electromagnética, por la sencilla razón de que la retina no es un plano geométrico $\alpha$, ni la continuidad electromagnética se interrumpe como un rayo proyectante (OA) en el punto o' de una sección proyectiva inexistente.

En óptica electromagnética la continuidad de la onda no se corta interrumpiéndose en ningún objeto, sino que "rebota" de objeto en objeto, variando en frecuencia según las leyes de absorción. El proceso de las partículas fotónicas en trayectoria, sin embargo, no se prolonga ad infinitum, sino que se detiene por el segundo principio de termodinámica, a través de la extinción calórica que convierte la onda sinocoidal en radiación térmica, cuya energía calórica se disipa según las leyes establecidas para la entropía. De manera que la onda electromagnética se interrumpe, pero no por una sección óptica propia de la geometría, sino por una extinción calórica propia de la termodinámica. En física no existe la cortadura sinocoidal contra el plano tangencial de la retina sino sólo la disipación calórica en el interior del globo ocular, que se comporta más como una "máquina térmica" que como una "caja oscura".

Esta última consideración nos permite pasar al segundo género de objeciones referidas a la óptica física. Los argumentos, en este punto, se dirigen hacia la consideración de la termodinámica y la óptica cuántica. 


\section{Objeciones desde la óptica física}

Bajo la perspectiva de la óptica física, el ojo no funciona como una "cámara oscura" renacentista sino más bien como una "máquina térmica" de Carnot, en cuanto se acerca al ideal de una caja de espectro negro radiante. Esta tesis es empleada por la escuela hiperrealista para negar el paradigma moderno que concibe el ojo como una cámara oscura. Este paradigma oftálmico pierde su aplicación en el ámbito neurocientífico, donde el ojo no se comporta como una cámara estenopeica al modo decimonónico, sino como un "horno de cuerpo negro" o una excelente aproximación al cuerpo gris ${ }^{34}$. El teorema de la "corteza retiniana" de Hering se desmonta desde las aportaciones de la termodinámica, dado que en la retina no se forma imagen ninguna en contra del mito cartesiano expuesto en su dióptrica.

Hasta donde pueden conciliarse la óptica electromagnética y la neurofisiología ${ }^{35}$, ambas permiten concluir que el ojo es una intrincada estructura organizada que forma un todo coherente y solidario con el cerebro, de modo que su función sería implementadora: maximiza la captura de energía que el sol emite en forma de fotones de luz visible y, tras un proceso de absorción, reirradia esta energía en forma de fotones infrarrojos. Puesto que cada uno de los fotones de luz visible tienen mayor energía que cada uno de los infrarrojos, los fotones que llegan a esa región del cerebro que es el fondo retiniano deben hacerlo en número menor que los fotones infrarrojos que dejan dicho órgano, de modo que la energía que entra en el órgano compensa la que lo abandona. Desde un punto de vista termodinámico, el ojo no capta luz ni, en consecuencia, asimila información alguna. Se limita a dar oportunidad a un cambio sustancial, en la conversión: ( $\alpha$ ) energía radiante $\rightarrow$ $(\beta)$ energía calórica, sin que quepa mantener la conservación del específico modo de ser ( $\alpha$ ), fotón, en ( $\beta$ ) cuerpo caliente. Toda la información que caracterizaba a (a), y que determinaba su índole como sistema físico, se perdió tras el proceso de corrupción posibilitado, a la sazón, por el ojo, al que (a) no comunicó nada. Como toda causa ocasional, el ojo es una coyuntura ineficaz, es decir, que no actúa y que, en este caso, se limitó a posibilitar la transformación de ( $\alpha$ ) en ( $\beta)$.

[34] Penrose, R.: La nueva mente del emperador. Barcelona: Mondadori, 1991, pp. 350ss. Ibídem: Las sombras de la mente: hacia una comprensión científica de la consciencia. Barcelona: Crítica, 1996, pp. 229-443. Ibídem: «Newton, teoría cuántica y realidad», en: Penrose, R. y Hawking, S.: Cuestiones cuánticas y cosmológicas. Madrid: Alianza, 1995. Penrose, R.: Lo grande, lo pequeño y la mente humana. Madrid: AKAL, 2006, pp. 49-111.

[35] Schnapf, J.: "How Photoreceptors Respond to Light", en Scientific American, April 1987. Baylor, D. A., Lamb, T. D. y Yau, K. W.: "Responses of retinal rods to single photons", en J. Physiol., n 288, March, 1979, pp. 613-634. Rieke, F. y Baylor, D. A.: "Origin of reproducibility in the responses of retinal rods to single photons", en Biophys J., 75(4), October, 1998, pp. 1836-1857. Ibídem: "Single-photon detection by rod cells of the retina", en Rev. Mod. Phys., 70, 1998, pp. 10271036. Hecht, S., Schlaer, S. y Pirenne, M. H.: "Energy, Quanta and vision", en Journal of the Optical Society of America, 38, 1942, pp. 196-208.

THÉMATA. Revista de Filosofía, Nº49 enero-junio (2014) pp.: 271-291

doi: 10.12795/themata.2014.i49.15 
Consideremos un haz estrecho de radiación electromagnética de intensidad I que incide sobre una región del espacio que contiene ese sistema físico denominado ojo. Si este no existiese, el haz continuaría hacia delante sin perturbación según una dirección bien determinada (la de incidencia) de modo que un eventual detector puesto en su camino mediría dicha intensidad I. Cuando hay sistemas físicos en el camino de la radiación, dicho detector marcará siempre una intensidad $\mathrm{I}<\mathrm{I}^{\prime}$, y diremos que el haz ha sufrido una cierta extinción. La pérdida de intensidad I - I' consta de dos partes en general: una es la intensidad radiada por el sistema físico en otras direcciones, que llamaremos según lo antedicho difusión, y la otra se debe a la transformación de la energía electromagnética en energía de otro tipo (generalmente calor) en el interior del sistema físico. Este último fenómeno recibe el nombre de absorción, de forma que podemos considerar la relación conceptual: "extinción = difusión + absorción".

Traducido a terminología clásica, "extinción" equivale a corrupción absoluta, no a mera alteración. Desde el punto de vista de la óptica termodinámica, el "ojo humano" sólo es una instancia favorable para trocar una forma de energía por otra. Lo mismo podría decirse desde la óptica cuántica, atendiendo a la $3^{a}$ acción básica de la electrodinámica cuántica tal como la estableció Fey$\mathrm{nman}^{36}$. De modo que el presupuesto en que el modelo heurístico del procesamiento de información se funda, queda desbancado por la base: la visión no es "una elaboración intracerebral a partir de información extracerebral", porque tal intercambio de información no cabe en el modelo termodinámico.

Con las evidencias que aporta la termodinámica, el psicofísico puede concluir que el ojo no contiene ninguna "imagen, o proyección, retiniana", ni supone una "pantalla interior" o un "mosaico retiniano", ni admite metáforas como la "retina cortical" o el "procesamiento de información visual". La naturaleza de la retina, gracias al microscopio y a la teoría celular, deja de concebirse como una superficie continua (un lago, un espejo, una placa de peltre, una película fotosensible) según el modelo geométrico del plano euclídeo. La retina no es un plano tangente paralelo a los objetos iluminados; de esta manera se rompe con el modelo dióptrico acuñado por Descartes y su alianza con la óptica electromagnética. Si además atendemos a las evidencias neurobiológicas, el psicobiólogo no puede tampoco tender un puente entre la "imagen" de la retina ocular y las diversas regiones de la corteza visual dado que sólo un $20 \%$ de los estímulos retinianos alcanzan la corteza occipital especializada en la visión. Esta selección refuerza la tesis hiperrealista que distingue desde Brunswik entre "atributos de la percepción" (o imagen visual) y su incorporación mediante las "dimensiones de los estímulos"37.

[36] Feynman, R.: Electrodinámica cuántica. Madrid: Alianza, 1990, pp. 90-95.

[37] Brunswik, E.: Perception and the representative design of psychological experiments. Berkeley: UCA Press, 1956, pp. 48-52.

THÉMATA. Revista de Filosofía, Nº49 enero-junio (2014) pp.: 271-291 doi: 10.12795/themata.2014.i49.15 
El idealista concibe el cerebro como causa eficiente o formal de la percepción visual; el hiperrealismo trata el cerebro como causa ocasional, es decir, le niega su condición de causa, sin caer por ello en el acausalismo. Se apoya tanto en la termodinámica como en la física cuántica para destruir este vínculo causal donde las apariencias son efectos de la actividad cerebral. El ojo quedaría reducido -como acabamos de ver- a una "causa ocasional", incapaz por su condición ocasional de ejercer ninguna acción. Sería una condición, más que una causa, al modo del "condicionalismo psico-fisiológico" de Max Verworn. Este es el fundamento principal de la teoría del "affordance" 38 dentro del hiperrealismo de la percepción directa de J. J. Gibson.

Esta crítica del hiperrealismo se agrava con las aportaciones de la neurología cuántica, que hacen insostenibles las interpretaciones idealistas de la óptica física y el electromagnetismo implícitos en su "cajanegrismo". El planteamiento idealista tiende a privilegiar el estudio de los sistemas macroscópicos asociados a la percepción visual y descuida parcialmente los aspectos microfísicos. De esta manera amputa la investigación neuriocientífica desde la base, al limitar la investigación al "canon modular" de Vernon B. Mountcastle. El hiperrealismo exonera la neurociencia de este "bloqueo macroscópico" que el representacionismo introduce sobre el cuerpo científico. El hiperrealismo no sólo admite las aportaciones macroscópicas de la neurología sino que considera clave para la comprensión del "affordance" el estudio de estas estructuras citoesqueléticas y su fisiología cuántica (microtúbulos y puentes MAP, agua "vicinal", clatrinas en el botón sináptico del axón, pozos cuánticos, etc.) ${ }^{39}$.

El hiperrealismo, al estar liberado del prejuicio idealista de la "cámara oscura", concibe la neurociencia desde el pluralismo ontológico. El hiperrealismo admite que puede desarrollarse actividad fisiológica cuántica decisiva para la cerebralización de la imagen vista sin que se desencadene actividad nerviosa macroscópica que pueda detectarla. Este realismo metodológico exige una consideración más detallada de la actividad neural macroscópica junto a la actividad microfísica, para determinar las funciones de ambos y su interacción recíproca, como reclama la "nanoneurología" para explicar la visión escotópica, las agnosias visuales, el fenómeno de la apercepción óptica, los estados anestésicos y un estudio más riguroso del sistema sensorio-motor y háptico de Lashley, entre otras cuestiones promisorias.

[38] Gibson, J. J.: «The Theory of Affordances», en: Shaw R. y Bransford J. (eds.), In Perceiving, Acting, and Knowing. NY: Erlbaum, 1977, pp. 67-82. Ibídem: The Ecological Approach to Visual Perception. Boston: Houghton Mifflin, 1979. Cardellicchio, P., Sinigaglia, C. y Costantini, M.: "The space of affordances: A TMS study", en Neuropsychologia, Volume 49, Issue 5, April 2011, pp. 1369-1372. Ibídem: "Affordances with the other's hand: A TMS study", en Soc Cogn Affect Neurosci, Mar 15, 2012, pp. 95-103.

[39] Hameroff, S.: «Consciousness, neurobiology and quantum mechanics», en: Tuszynski, J. (ed.), en The Emerging Physics of Consciousness, Springer, 2006. Hameroff, S. y Kaszniak, S. (eds): Toward a Science of Consciousness, MIT Press, 1996. Lockwood, M.: Mind, Brain, and the Quantum. Oxford: Blackwell, 1989.

THÉMATA. Revista de Filosofía, No 49 enero-junio (2014) pp.: 271-291

doi: 10.12795/themata.2014.i49.15 


\section{Objeciones desde la metodología neurológica}

En tercer lugar el hiperrealismo centra su crítica en la metodología de las neurociencias.

Desde la perspectiva idealista del anatomista, del fisiólogo o del neurólogo, todos los "contenidos sensoriales" cartografiados por vía introspectiva como "percepción de los colores" habrán de merecer la consideración de apariencias o de fenómenos causados por la actividad nerviosa del cerebro. La reducción de tales apariencias a sus correlatos neurales supone una reducción desde estas apariencias inmanentes con los procesos cerebrales y sus correlatos orgánicos. Esta reducción se practica sistemáticamente con las actuales técnicas de investigación de los procesos de percepción visual (implantación de electrodos en las células de la corteza visual, cortes paralelos en la superficie cortical que se colorean con citocromo oxidasa, blobs para poner en evidencia la actividad metabólica de la célula, tomografía por emisión de positrones o PET-scanner, fMRI, etc). Mediantes estos análisis anatómico-funcionales se irán determinando las áreas neuronales que intervienen en cada ocasión. Pero el idealista incurre de esta manera en lo que llamaremos "falacia idealista de identificación" entre los correlatos neurales y la percepción visual. La expresión más radical de esta falacia es la creencia de que, partiendo de las áreas o circuitos localizados, podremos mediante una intervención pertinente ("emulaciones completas de estimulación cerebral", réplicas psicofísicas homotéticas, etc.) reconstruir las apariencias desde sus fundamentos ${ }^{40}$.

La falacia radica en no advertir que las delimitaciones de las diferentes realidades cerebrales no se han llevado a cabo desde el propio cerebro, sino precisamente desde las apariencias. No vemos desde el cerebro porque siempre estudiamos un cerebro ya visto. No es la "cartografía que el cerebro hace del cerebro" lo que nos lleva, por construcción, a un conocimiento efectivo de las apariencias introspectivas; es la cartografía de las apariencias la que nos conduce a la cartografía del cerebro. Es una ilusión creer que es la cartografía del cerebro la que nos conduce a la cartografía de las apariencias. Estamos ante un dialelo característico. Si distingo en V4 diferentes áreas especializadas en la percepción de los colores puedo tener la impresión de que controlando las neuronas de esta área V4 estoy construyendo los colores. Lo que ocurre es que si no tuviese ya diferenciados los contenidos cromáticos no podría obtener el concepto de esas áreas que, por sí mismas, nada nos dirían acerca de los colores.

Efectivamente, los fosfenos de W. G. Penfield, los cromatófenos de K. G. Beckers o la postimagen de C. S. Sherrington, son hechos extraordinarios que no se confunden nunca con la percepción directa habitual. Desde estos fenómenos entópticos, y otros que pudieran aducirse, no se explica la percepción natu-

[40] Cfr. Crick, F.: La búsqueda científica del alma: una revolucionaria hipótesis para el siglo XXI. Madrid: Debate, 1994.

THÉMATA. Revista de Filosofía, Nº49 enero-junio (2014) pp.: 271-291

doi: 10.12795/themata.2014.i49.15 
ral aunque sean fenómenos inherentes a las condiciones cerebrales del sujeto operatorio. En fisiología de la visión las áreas especializadas se han localizado con técnicas de estimulación mediante microelectrodos, por la ablación de los núcleos pertinentes en primates, y por la confrontación con observaciones clínicas en humanos (acromatopsias provocadas por lesiones vasculares en V4, acinetopsias por lesiones localizadas en el área V5, etc.). Pero supone una "petición de principio" interpretar estos hechos como pruebas del "idealismo neurocientífico" ("el cerebro crea las imágenes visuales") cuando es precisamente el idealismo el que sirve como criterio de interpretación previo.

Por otro lado, si desde el idealismo se niegan los colores como "subjetivos" también deberían negarse las formas, la extensión, el movimiento, la localización espacial de los cuerpos, sus texturas, así como su resistencia al tacto o la dureza. Se deberían, por tanto, negar tanto los sensibles propios aristotélicos, o cualidades primarias modernas (o amodales de la psicología cognitiva), como también las cualidades secundarias o amodales, los sensibles comunes de aquella tradición ${ }^{41}$. Por esta vía se llega a la negación misma de la materia como ya hiciera el neuropsiquiatra Jules Seglas y su teoría de la realidad como "alucinación verdadera". En las construcciones mentales idealistas no sólo habría que reconstruir el color sino también la figura e incluso su situación espacial, porque la forma que supuestamente "construye" mi cerebro no es percibida en su interior sino allí, en el árbol mismo percibido, originando la consabida distinción epistemológica entre "objeto conocido" y "objeto de conocimiento". De esta manera se desemboca en el "nihilismo del referente" que Jacobi denunció en el "idealismo absoluto" de Fichte, y que podríamos trasladar al "idealismo neural" ejercido por ciertos neurocientíficos de la visión.

\section{El hiperrealismo en las neurociencias}

La segunda manera de comprender el aparato retiniano asume que no hay más imagen que la imagen vista, y de que ésta no es por consiguiente, copia ni reproducción causada por una imagen exterior. El hiperrealismo distingue, por tanto, entre factores apotéticos (imágenes vistas o presencias percibidas de modo inmediato) y factores paratéticos (conexiones de interacción contigua, tales como ondas electromagnéticas, impulsos nerviosos, reacciones enzimáticas en las neuronas, etc. $)^{42}$. De este modo, el acto de visión apotético no empieza en la actividad retiniana sino en el mismo objeto y abarca multitud de niveles psicobiológicos en su dimensión paratética. El factor paratético se identifica

[41] Grossmann, R.: Ontología, realismo y empirismo. Madrid: Encuentro, 2010, pp. 42-78. Cfr. Ibídem: La estructura de la mente. Barcelona: Labor, 1969. La existencia del mundo: introducción a la ontología. Madrid: Tecnos. 2007.

[42] García Sierra, P.: «Apotético, paratético», en: Diccionario filosófico, Oviedo, Pentalfa, 1999. Cfr. Bueno, G.: Teoría del cierre categorial. Vol. V. Oviedo: Pentalfa, 1995, pp. 1387-1388.

THÉMATA. Revista de Filosofía, No 49 enero-junio (2014) pp.: 271-291 doi: 10.12795/themata.2014.i49.15 
con las catexias, o saliencias, de la teoría de la Gestalt, mientras que el factor apotético lo hace con las pregnancias; las conexiones paratéticas abarca también los "estímulos distales" instituidos por Brunswik para la psicofísica. Pero incluye del mismo modo la contigüidad no-local de la "nanobiología". Por tanto, el neorrealismo admite, al margen de los factores paratéticos macroscópicos, factores paratéticos de tipo cuántico, tales como las emisiones de microondas en los centriolos de las neuronas a $15 \mathrm{~Hz}$ de frecuencia o las singularidades de Bose-Einstein en el interior de los microtúbulos.

La relación entre ambos aspectos de la percepción visual según la teoría del "neuro-realismo" quedaría establecida como sigue:

a) Por lo que se refiere a la percepción apotética, el espacio de la luz es un espacio estricto de proyección, físicamente reconocido como tal. Quiere esto decir que un haz luminoso no puede ser propiamente seccionado, puesto que cada punto de la pantalla que lo interrumpe se convierte, a su vez, en un nuevo centro independiente de proyección, y así hasta el infinito. Así, la única sección que admite la luz es la sección que ejerce la operación visual de la conciencia. Bergson lo formaliza de la siguiente manera: «Sea la percepción del punto P: el punto $\mathrm{P}$, los rayos que emite y la retina forman un todo solidario; el punto luminoso $\mathrm{P}$ forma parte de ese todo, y es precisamente en $\mathrm{P}$ donde se forma $\mathrm{y}$ es percibida la imagen de $\mathrm{P}{ }^{43}$.

Cuando percibo la luna, el proceso que nos lleva a ella no comienza en la retina, porque lo que acontece en ella es tan sólo una prolongación de unas ondulaciones luminosas que parten de la luna. Por tanto, la integridad del proceso va de la luna misma al cerebro. Y gracias a ello, la percepción está presente en el término inicial mismo del proceso, esto es, en la luna misma. Percibir es estar mentalmente en la cosa tal como es ella misma. La percepción va directamente a la realidad inmediata; no hay estado representativo intermediario entre la luna y la mente. "Cuando percibo la luna, ¿se puede decir que yo estoy en la luna? Sin embargo, ¿es más fácil de concebir que la luna está en mí en la percepción, que decir que yo estoy en la luna? (...) Nos invita a pensar cómo, para la mente, todo, hasta lo más lejano, está presente. Positivamente, es claro que cuando percibo la luna yo no estoy físicamente en ella; esto es evidente. La presencia no es topográfica. Pero no se trata de esto, sino de que estoy mentalmente en la luna. Y este estar, por muy mental que sea, es perfectamente real» ${ }^{44}$.

b) Por lo que respecta de los factores paratéticos, el hiperrealismo no pretende relacionar un "percepto" o "qualia" (representación visual en la mente del observador) con el estímulo psicofísico exterior al observador, ni la activi-

[43] Ruyer, R.: El cuerpo y la conciencia. Buenos Aires: Paidós, 1961, pp. 15. Bergson, H.: Materia y memoria. Buenos Aires: Cactus, 2006, p. 30ss. Ibídem: Las dos fuentes de la moral y de la religión. Madrid: Ediciones Altaya, 1999, p. 270ss.

[44] Zubiri, X.: Cinco lecciones de filosofía. Madrid: Alianza, p. 181.

THÉMATA. Revista de Filosofía, No 49 enero-junio (2014) pp.: 271-291

doi: 10.12795/themata.2014.i49.15 
dad electroquímica del sistema nervioso, sino que considera al animal como detector de disponibilidades (affordances) que el medio le ofrece con ocasión de esos estímulos "distales" (respecto a la corteza cerebral) y "proximales" (en relación a la fisiología, macroscópica y cuántica, de esa corteza ${ }^{45}$. A través de la maquinaria retiniana y la actividad del córtex cerebral (área 17 de Broadmann) el nicho ecológico percibido va a quedar cerebralizado y conectado a la acción corporal, sin la mediación de una representación vicaria.

\section{Conclusión}

Es obligado mencionar una concepción de la verdad y la apariencia que podría denominarse como "realismo óptico inmediatista", o "realismo constructivista" ${ }^{46}$, y que va tomando cuerpo en numerosos científicos técnicos (fisiólogos, neurólogos, ingenieros informáticos) que se ocupan de investigar los mecanismos de la visión de los hombres y de los animales, en general. Y tanto de la investigación natural como de las prótesis artificiales orientadas a proporcionar a los ciegos la posibilidad de una percepción óptica, como las microcámaras que forman el "ojo de Dobelle".

Sin embargo, este "neuro-realismo", "neorealismo naturalista" o "realismo ecológico", no es propiamente una concepción científica que pueda considerarse constitutiva de la "capa básica" de la fisiología comparada de los sistemas ópticos de los animales, sino más bien una filosofía mundana, una de esas "filosofías académicas de los científicos" de las que hablaron los althusseranos hace cuarenta años. Y esto sin perjuicio de reconocer la gran probabilidad de que este realismo constructivista pueda ser reinterpretado desde alguna concepción filosófica general que se considere favorecida por él.

De esta manera, esta filosofía mundana aparece como incompatible de ciertas filosofías académicas que quedan refutadas tales como el idealismo o el constructivismo absoluto. Otras filosofías académicas de la tradición quedarán privilegiadas o, incluso, podrán realizar una labor de crítica, respecto de las ingenuidades mundanas de esta conciencia filosófica acrítica obtenida por los neuro-fisiólogos a partir de sus experiencias positivas en los laboratorios. Empero, no cabrá hablar de "realismo ingenuo", pues es el idealismo quien queda en tela de juicio bajo la crítica de este mismo realismo que las técnicas y prácticas científicas vehiculan.

En este sentido, el realismo -concebido en el marco de una teoría científica de la visión- se nos presenta ante todo como una alternativa al idealismo mediatista, asociado al representacionismo moderno de tradición cartesiana y

[45] Bruce, V. y Green, P. R.: Percepción visual: manual de fisiología, psicología y ecología de la visión. Barcelona: Paidós, 1994.

[46] Zeki, S.: "La construcción de imágenes por el cerebro", en Mundo científico, nº 105, pp. 861ss.

THÉMATA. Revista de Filosofía, Nº49 enero-junio (2014) pp.: 271-291

doi: 10.12795/themata.2014.i49.15 
kantiana, según el cual poseemos mediaciones vicarias que están en la mente en lugar de la realidad objetiva. Según este idealismo existiría una diferencia entre sujeto y objeto de conocimiento, así como un isomorfismo en el que la visión verdadera sería la visión que logra la reproducción isológica del objeto en el cerebro y, ante todo, en la retina. Ha sido el desarrollo de las diversas ciencias sintetizadas en el proyecto neuro-científico el que ha hecho entrar en grave crisis este modelo gnoseológico del "idealismo ingenuo". 


\section{Referencias bibliográficas:}

\section{Libros:}

Barwise, J. y Perry, J.: Situaciones y actitudes. Madrid: Ed. Visor, 1992. Benton, A.: History of Neuropsychology: Selected Papers. NY: Oxford, 2000. Bergson, H.: Las dos fuentes de la moral y de la religión. Madrid: Ediciones Altaya, 1999.

Bergson, H.: Materia y memoria. Buenos Aires: Cactus, 2006.

Berkeley, G.: Ensayo de una nueva teoría de la visión. Madrid: Aguilar, 1973.

Brady, M.: «Computational vision», en: Broadbent, D. (ed.): The simulation of human intelligence. Oxford: Blackwell, 1993.

Bruce Goldstein, E.: Sensación y percepción. Méjico: International Thomson Editores, 2006.

Bruce, V. y Green, P. R.: Percepción visual: Manual de fisiología, psicología y ecología de la visión. Barcelona: Paidós, 1994.

Brunswik, E.: El marco conceptual de la psicología. Madrid: Debate, 1989.

Brunswik, E.: Perception and the representative design of psychological experiments. Berkeley: UCA Press, 1956.

Bueno, G.: Televisión: apariencia y verdad. Barcelona: Gedisa, 2000.

Crick, F.: La búsqueda científica del alma: una revolucionaria hipótesis para el siglo XXI. Madrid: Debate, 1994.

Descartes, R.: Dióptrica. Alfaguara: Madrid, 1991.

Feynman, R.: Electrodinámica cuántica. Madrid: Alianza, 1990.

Finger, S.: Origins of neuroscience: a history of explorations into brain function. NY: Oxford, 1994.

Finger, S.: Minds Behind the Brain: A History of the Pioneers and their discoveries. NY: Oxford, 2000.

Frisby, J. P.: Del ojo a la visión. Madrid: Alianza, 1987.

García Sierra, P.: "Apotético, paratético», en: Diccionario filosófico, Oviedo, Pentalfa, 1999.

Geischeider, G. A.: Psychophysics: The Fundamentals. New Jersey: Erlbaum, 1997.

George, F. H.: Cibernética y biología. Madrid: Alhambra, 1968.

Gibson, J. J.: La percepción del mundo visual. Ed. Infinito: Buenos aires, 1974. Gibson, J. J.: The Ecological Approach to Visual Perception. Boston: Houghton Mifflin, 1979.

González Quirós, J. L.: Mente y cerebro. Madrid: Iberediciones, 1994.

Graham, Ch.: Vision and visual perception. NY: John Wiley and Sons, 1965.

Grossmann, R.: La estructura de la mente. Barcelona: Labor, 1969.

Grossmann, R.: La existencia del mundo: introducción a la ontología. Madrid: Tecnos. 2007. 
Grossmann, R.: Ontología, realismo y empirismo. Madrid: Encuentro, 2010.

Hameroff, S. y Kaszniak, S. (eds): Toward a Science of Consciousness, MIT Press, 1996.

Hochberg, J. E.: La percepción. México: Ed. UTEHA, 1968.

Hubel, D. H.: Ojo, cerebro y visión. Barcelona: Ed. Investigación y ciencia, 1998. Jansson, G., Sture Bergström, S. y Epstein, W.: Perceiving: Events and Objects. Londres: Routledge, 1994.

Jeannerod, M.: De la physiologie mentale. Historie des relations entre la phychologie et la biologie. París: Odile Jacob, 1996.

Kenny, A.: The Metaphysics of Mind. Oxford: Oxford University Press, 1992.

Lockwood, M.: Mind, Brain, and the Quantum. Oxford: Blackwell, 1989.

Luna, D. y Tudela, P.: Percepción visual. Madrid: Trotta, 1995.

Mach, E.: The principles of phisical optics. Londres: Dover publications, 2003.

Marr, D.: Visión: una investigación basada en el cálculo acerca de la representación y el procesamiento humano de la información visual. Madrid: Alianza, 1985.

Martínez Verdú, F. M.: Fundamentos de visión binocular. Valencia: PUV, 2004. Merleau-Ponty, M.: El ojo y el espíritu. Barcelona: Paidós, 1986.

Newton, I.: Óptica. Madrid: Alfaguara, 1977.

Nielsen, M. y Chuang, I.: Quantum Computation and Quantum Information. Cambridge: Cambridge University Press, 2000.

Penrose, R.: La nueva mente del emperador. Barcelona: Mondadori, 1991.

Penrose, R. y Hawking, S.: Cuestiones cuánticas y cosmológicas. Madrid: Alianza, 1995.

Penrose, R.: Las sombras de la mente: hacia una comprensión científica de la consciencia. Barcelona: Crítica, 1996.

Penrose, R.: Lo grande, lo pequeño y la mente humana. Madrid: AKAL, 2006.

Pieratoni, R.: El ojo y la idea. Barcelona: Paidós, 1984.

Polyak, S.: The vertebrate visual system. Chicago: University of Chicago Press, 1957.

Pribram, K. H.: Brain and perception: holonomy and structure in figural processing. Hillsdale: Erlbaum, 1991.

Pribram, K. H.: Rethinking neural networks: quantum fields and biological data. Hillsdale: Erlbaum, 1993.

Ruyer, R.: El cuerpo y la conciencia. Buenos Aires: Paidós, 1961.

Saumells, R.: Dialéctica del Espacio. Madrid: CSIC, 1953.

Saumells, R.: La ciencia y el ideal metódico. Madrid: Rialp, 1958.

Saumells, R.: La intuición visual. Madrid: Parteluz, 1994.

Schwartz, S. H.: Visual Perception: a clinical orientation. Connecticut: Appleton and Lange, 1999.

Wittgenstein, L.: Observaciones sobre filosofía de la psicología. Méjico: UNAM, 1997.

Zeki, S.: Una visión del cerebro. Barcelona: Ariel, 1995. 


\section{Artículos:}

Barwise, J. y Perry, J.: "Situations and attitudes", en Journal of philosophy, 78, nº 11, 1981, pp. 668-691.

Baylor, D. A., Lamb, T. D. y Yau, K. W.: "Responses of retinal rods to single photons", en J. Physiol., no 288, March, 1979, pp. 613-634.

Brunswik, E.: "Distal focuding of perception: size-constancy in a representative sample of situations", Psychol. Monog., 56, $\mathrm{n}^{\circ} 254$.

Deutsch, D.: "Quantum theory, the Church-Turing principle and the universal quantum computer", en Proceedings of the Royal Society of London, A400 (1818), July, 1985, pp. 97-117.

Gibson, J. J.: «The Theory of Affordances», en: Shaw R. y Bransford J. (eds.): In Perceiving, Acting and Knowing. NY: Erlbaum, 1977

Hameroff, S.: "Consciousness, neurobiology and quantum mechanics», en: Tuszynski, J. (ed.), en: The Emerging Physics of Consciousness. Springer, 2006. Hecht, S., Schlaer, S. y Pirenne, M. H.: "Energy, Quanta and vision", en Journal of the Optical Society of America, 38, 1942, pp. 196-208.

Jung, R.: "Sensory research in historical perspective: some philosophical foundations of perception", en: Darian-Smith, I (ed.): Handbook of Physiology, American Physiological Society. Maryland: Bethesda, 1984.

Rayo, A.: "Computación cuántica", Investigación y Ciencia, 405, junio 2010, pp. 92-93.

Rieke, F. y Baylor, D. A.: "Origin of reproducibility in the responses of retinal rods to single photons", en Biophys J., 75(4), October, 1998, pp. 1836-1857. Schnapf, J.: "How Photoreceptors Respond to Light", en Scientific American, April 1987.

Zeki, S.: "La imagen visual en la mente y en el cerebro», en Investigación y ciencia, $\mathrm{N}^{\circ} 194,1992$, pp. 26-35.

Zeki, S.: "La construcción de imágenes por el cerebro", en Mundo científico, $1984, \mathrm{n}^{0} 105$. 
